\title{
Endobronchial secretion of interleukin-13 following local allergen challenge in atopic asthma: relationship to interleukin-4 and eosinophil counts
}

\author{
C. Kroegel*, P. Julius**, H. Matthys**, J-C. Virchow Jr**, W. Luttmann**
}

Endobronchial secretion of interleukin-13 following local allergen challenge in atopic asthma: relationship to interleukin-4 and eosinophil counts. C. Kroegel, P. Julius, H. Matthys, J-C. Virchow Jr, W. Luttmann. @ERS Journals Ltd 1996.

ABSTRACT: We investigated the secretion of interleukin (IL)-13 into the airways in 10 mild allergic asthmatics by employing local allergen challenge, and compared the data both to IL-4 levels and eosinophil numbers obtained by bronchoalveolar lavage (BAL).

Appropriate allergen or saline were endoscopically instilled into different airway segments, which were lavaged $10 \mathrm{~min}$ and $18 \mathrm{~h}$ after allergen or sham challenge. IL-4 and IL-13 were measured in unconcentrated BAL fluid using a double sandwich enzymes-linked immunosorbent assay (ELISA).

Endobronchial allergen challenge induced a highly significant increase in the numbers of eosinophils after $18 \mathrm{~h}$ in the allergen exposed segment. Ten minutes following allergen exposure, low levels of IL-4 and IL-13 could be detected, whilst concentrations of both cytokines were significantly raised $18 \mathrm{~h}$ following local allergen exposure. In contrast to IL-4, the concentration of IL-13 strongly correlated with the eosinophil numbers found $18 \mathrm{~h}$ post-allergen challenge.

The results suggest that interleukin-13 is actively secreted during the late asthmatic response in mild asthmatic subjects. In view of its action on eosinophils and other cell types, we conclude that interleukin-13, in addition to interleukin-4, may play an important role in the pathogenesis of eosinophil-related inflammation, such as bronchial asthma.

Eur Respir J., 1996, 9, 899-904.
*Dept IV, Pneumology, Medical University Clinics, Friedrich-Schiller University, Jena, Germany. **Dept Pneumology, Medical University Clinics, Freiburg, Germany.

Correspondence: C. Kroegel

Dept IV Pneumology

Medical University Clinics

Friedrich-Schiller University

Erlanger Allee 101

D-07747 Jena

Germany

Keywords: Allergic asthma asthma pathogenesis

bronchoalveolar eosinophils

interleukin-4

interleukin-13

segmental allergen provocation

Received: October 261995

Accepted after revision March 131996

Supported by the State Baden-Württemberg, Kernforschungszentrum Karlsruhe, PUG Germany (92/003/LUVA).
Bronchial asthma is now widely-accepted as a chronic inflammatory disease of the airways and characterized by eosinophil infiltration of airway tissue (for review see [1]). A large body of evidence suggests that eosinophils represent a central effector cell at the distal end of the immune response, determining severity and chronic course of asthma via the release of a spectrum of cytotoxic mediators and proteins [2]. In addition, the number of eosinophils in sputum and airways has been shown to correlate with the airway damage and severity of bronchial obstruction, as measured by forced expiratory volume in one second (FEV1) as well as airway conductance [3-5], and inversely correlates with the sensitivity of the airways to methacholine [6]. Similarly, a recent study [6] demonstrated that the number of eosinophils in the blood, bronchoalveolar lavage (BAL), and bronchial mucosa correlates with the degree of asthma, assessed by a clinical scoring method.

Although the precise mechanism underlying eosinophil tissue accumulation and activation remains to be elucidated, there is increasing evidence that T-helper cells with a type 2 (Th2) cytokine phenotype, mediate and maintain the allergic airway response in asthma, including eosinophil function and survival [7-12]. For example, eosinophil infiltration and disease intensity was found to be associated with the production of Th2 cell type cytokines, such as interleukin (IL)-4 and IL-5 [19]. However, not all the functions of eosinophils could be explained by these cytokines $[8,10,11]$.

Recently, IL-13 has been identified as representing another cytokine produced by Th2 cells in mice [12,13]. The homologue human IL-13 is a pleotropic cytokine, which modulates the functions of several cell types implicated in the pathogenesis of allergic inflammation, including B-cells, endothelial cells, mast cells and eosinophils [14-21]. However, to our knowledge, only little information on the production of the biological activity of IL13 in atopic asthma is available. Thus, in the present study, we investigated the secretion of IL-13 into lavage fluid following endobronchial allergen challenge in asthmatic subjects. In addition, the relationship between IL13 and IL-4, as well as airway cell differential counts, was assessed.

\section{Patients and methods}

Ten nonsmoking mild-to-moderate atopic asthmatics (seven males and three females), 26-41 yrs of age (mean \pm SEM age $29 \pm 6$ yrs) with a minimum duration of asthma 
Table 1. - Clinical details of the subjects studied

\begin{tabular}{lc}
\hline Age yrs & $29 \pm 6(26-41)$ \\
Sex M/F & $7 / 3$ \\
Duration of asthma yrs & $12 \pm 9(2-27)$ \\
Other atopic manifestations n & \\
$\quad$ Rhinitis/rhinoconjunctivitis & 1 \\
$\quad$ Atopic dermatitis & 1 \\
Food allergy & $103 \pm 12(92-130)$ \\
FEV1\% pred & $97 \pm 14(75 \pm 113)$ \\
IVC \% pred & $82 \pm 6(75-98)$ \\
FEV1/VC & 8 \\
Skin-prick test (+++ positive) & 2 \\
Birch pollen & \\
Grass pollen & $475 \pm 509(98-2217)$ \\
Total IgE kU.L-1 & $>3.5$ in all subjects \\
Specific IgE\# kU.L-1 & 6 \\
Current medication & \\
$\beta_{2}$-agonists p.r.n. & \\
\hline
\end{tabular}

M: male; F: female; FEV1: forced expiratory volume in one second; IVC: inspiratory vital capacity; IgE: immunoglobulin E. \#: Kabi Pharmacia CAP system (Uppsala, Sweden).

of more than $2 \mathrm{yrs}$ (mean \pm SEM duration $12 \pm 9 \mathrm{yrs}$ ) were studied. Allergic asthma was defined as described previously [22]. The patients were selected on the basis of: 1) a history of intermittent wheezing, chest tightness, cough and sputum production either spontaneously or exercise-induced; 2) a positive skin-prick test to common inhalant allergens (birch pollen $\mathrm{n}=8$, or grass pollen $\mathrm{n}=2$; Abelló, Bornheim, Germany) and a cutaneous late reaction within $6 \mathrm{~h}$ after challenge; 3) increased specific immunoglobulin E (IgE) for the relevant allergen (Kabi Pharmacia CAP system, Uppsala, Sweden); 4) baseline FEV1 $>90 \%$ of predicted value; 5 ) increased bronchial responsiveness as determined by a modified bronchoprovocation test with carbachol and total or partial reversibility following administration of $\beta_{2}$-agonists as described previously [9]; 6) stable clinical conditions, with no acute asthma attack and no respiratory tract infection in the past 2 months; and 8) no treatment other than rescue $\beta_{2^{-}}$ adrenergic drugs, which were discontinued at least $24 \mathrm{~h}$ before the study (table 1). All patients were informed about the nature and the scope of the study and gave their written informed consent. The study was approved by the Ethics Committee of the University of Freiburg.

Bronchoscopy, segmental allergen challenge and BAL were performed as described previously [23]. In short, allergen (250 PNU in $2.5 \mathrm{~mL}$ saline) was instilled into the medial basal segment of the right lower lobe (B7 right) and into the medial segment of the right middle lobe (B5 right), whilst sham challenge ( $2.5 \mathrm{~mL}$ saline) was performed in the inferior lingular bronchus (B5 left) and one segment of the left lower lobe. Both the allergenand sham-challenged segments were lavaged using 100 $\mathrm{mL}$ of prewarmed saline after $10 \mathrm{~min}$ and $18 \mathrm{~h}$. BAL fluids (BALF) from antigen and sham challenge sites were collected separately and processed for differential counts and cytokine measurement.

Cytological examination of BALF was performed after cytocentrifugation and staining with May-Grünwald Giemsa. The relative proportions of the various leucocyte subpopulations were determined by a cell differential count of 1,000 cells.

IL-13 was quantified using commercially available enzyme-linked immunosorbent (ELISA) assay (Bender and Co., Vienna, Austria) according to the manufacturers instructions. Standard curves were constructed in pooled BALF and detection limits of $1 \mathrm{pg} \cdot \mathrm{mL}^{-1}$ established by spiking wells with recombinant cytokine. No cross-reactivity with other cytokines was observed. Measurements were performed in duplicate and expressed as means from both determinations.

For determination of IL-4 in the BALF, ELISA plates (Maxisorp, Nunc, Denmark) were coated with $2 \mu \mathrm{g} \cdot \mathrm{mL}^{-1}$ of a monoclonal mouse anti-human IL-4 serum (Clone IL-41; PharMingen, San Diego, CA, USA) in coating buffer (0.1 $\left.\mathrm{M} \mathrm{NaHCO}_{3}, \mathrm{pH} 8.0\right)$ over $6 \mathrm{~h}$ at room temperature, washed with phosphate-buffered saline (PBS) containing $0.05 \%$ Tween, and saturated with $3 \%$ bovine serum albumin (BSA) dissolved in PBS, pH 7.5. Serial dilutions of peritoneal lavage fluid plus recombinant IL4 (PDH, Hannover, Germany) were then applied to each well and incubated overnight at $4^{\circ} \mathrm{C}$. A peroxidase conjugated monoclonal rat anti-human IL-4 antibody (Clone MP4-25D2, PharMingen, San Diego) was added for 45 min at room temperature. After extensive washings with PBS/Tween, bound antibodies were revealed by application of $200 \mu \mathrm{L}$ tetramethylbenzidine (TMB)- $\mathrm{H}_{2} \mathrm{O}_{2}$-substrate solution containing $20 \mathrm{mM} \mathrm{TMB}$, and $50 \mathrm{mM} \mathrm{H}_{2} \mathrm{O}_{2}$

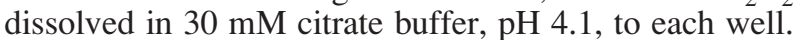
Following incubation for $15 \mathrm{~min}$ at room temperature, the reaction was stopped by adding, $1 \mathrm{M}$ sulphuric acid and colour intensity read at $450 \mathrm{~nm}$, photometrically. The results were derived from a standard curve established with human recombinant IL-4. The sensitivity of the assay was $10 \mathrm{pg} \cdot \mathrm{mL}^{-1}$. There was no cross-reactivity with other cytokines. The assay was log linear from 0.010 to $500 \mathrm{ng} \cdot \mathrm{mL}^{-1}$ using recombinant interferon (IFN- $\gamma$ ). The r-value of the standard curve was $>0.95(n=13)$. The intra-assay variation was 3-7\%, whilst interassay (dayto-day) reproducibility was $5-15 \%$.

All data were analysed nonparametrically using MannWhitney U-test for paired and unpaired variates, respectively. Statistical significance was claimed when p-value was less than 0.05 . The data in the text and figures are expressed as median and range unless otherwise stated. Correlations between continuous variables were calculated using Spearman's rank correlation test and expressed as the correlation coefficient $r_{s}$.

\section{Results}

Clinically, the deposition of allergen into two different segments of the right lung was well tolerated by all subjects. Although mean FEV1 in \% of predicted dropped from $102 \pm 12 \%$ before allergen challenge to $89 \pm 11 \% 10$ min after allergen challenge, this change was not statistically significant and dyspnoea was not reported in any of the subjects. Instillation of the allergen-containing solutions through a bronchoscope induced an immediate bronchoconstriction with swelling of the airway mucosa, leading to partial airway closure in all patients studied, which had disappeared after $18 \mathrm{~h}$.

BALF recovered from the sham-challenged segments ranged $26-66 \mathrm{~mL}(41 \pm 12.6 \mathrm{~mL}$; mean $\pm \mathrm{SEM})$ at $10 \mathrm{~min}$ and 35 to $63(49 \pm 3.2) \mathrm{mL}$ at $18 \mathrm{~h}$. In the allergen challenged segment which was lavaged $10 \mathrm{~min}$ after challenge, BALF recovery ranged $22-55 \mathrm{~mL}(39 \pm 3.5 \mathrm{~mL})$, 
and in the segment lavaged $18 \mathrm{~h}$ after allergen challenge

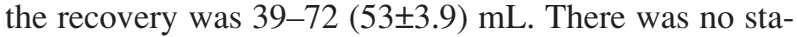
tistically significant difference between the percentage of BALF recovered in the three different segments.

At 10 min postchallenge, no change was observed either in the differential count or in the absolute cell number between antigen and control sites (data not shown). In contrast, after $18 \mathrm{~h}$, total cell recovery increased from (median) $75 \times 10^{3} \cdot \mathrm{mL}^{-1}$ (range $14-289$ ) and $69 \times 10^{3} \cdot \mathrm{mL}^{-1}$ (17-159) in the 10 min control and allergen segment, respectively, (NS), to $171 \times 10^{3} \cdot \mathrm{mL}^{-1}(87-431)$ in the shamchallenged (NS) and $469 \times 10^{3} \cdot \mathrm{mL}^{-1}(165-780)$ in the antigen-challenged site $(\mathrm{p}<0.01)$. This increase was mainly due to a highly significant increase in eosinophils at $18 \mathrm{~h}$ (19-fold compared to control) after segmental allergen provocation $\left(10 \mathrm{~min}\right.$ control: $0.9 \times 10^{3} \cdot \mathrm{mL}^{-1}(0-11) ; 10$ min allergen: $1.1 \times 10^{3} \cdot \mathrm{mL}^{-1}(0-13),(\mathrm{NS}) ; 18 \mathrm{~h}$ control: $5 \times 10^{3} \cdot \mathrm{mL}^{-1}(0-24) ; 18 \mathrm{~h}$ allergen: $93 \times 10^{3} \cdot \mathrm{mL}^{-1}(18-516)$ $(\mathrm{p}<0.0005$, compared both to the control and $10 \mathrm{~min}$ values). Other cell types also increased at $18 \mathrm{~h}$ postchallenge but not to the extent observed with eosinophils (neutrophils sixfold $(\mathrm{p}<0.002)$; lymphocytes fourfold $(\mathrm{p}<0.01)$; and macrophages twofold (NS)).

In order to determine whether IL-13 is produced in the airways following allergen exposure, the concentration of this cytokine was measured in unconcentrated BALF $10 \mathrm{~min}$ and $18 \mathrm{~h}$ following local allergen challenge and $18 \mathrm{~h}$ after sham saline challenge, employing a new IL13-specific sandwich ELISA. As depicted in figure 1, IL-13 concentrations in the BALF of all 10 subjects obtained from both allergen-exposed and sham-challenged segments at $10 \mathrm{~min}$ were close to the lower detection level (control $0.58(0-2.6) \mathrm{pg} \cdot \mathrm{mL}^{-1}$; antigen $0.55(0-2.5)$ $\left.\mathrm{pg} \cdot \mathrm{mL}^{-1}\right)$. A comparable low IL-13 concentration was observed in the lavage fluid obtained from the shamchallenge segment at $18 \mathrm{~h}$ postchallenge (0.5 (0-0.9) $\left.\mathrm{pg} \cdot \mathrm{mL}^{-1}\right)$. In contrast to both the $10 \mathrm{~min}$ antigen and $18 \mathrm{~h}$ control segments, IL-13 levels were significantly raised to $7.4(2.5-85.6) \mathrm{pg} \cdot \mathrm{mL}^{-1}$ in BALF recovered from the

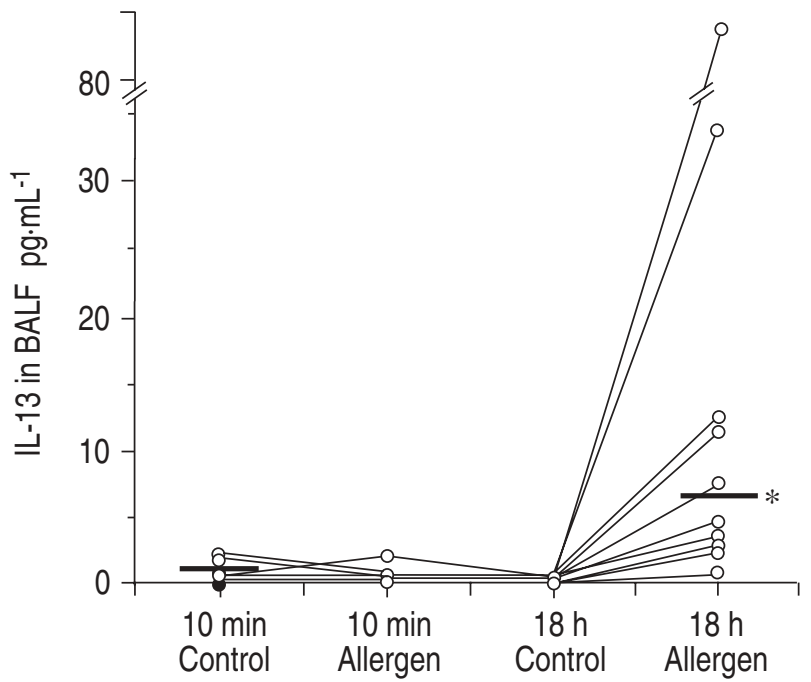

Fig. 1. - Concentrations of IL-13 in the BALF obtained 10 min and $18 \mathrm{~h}$ after segmental allergen provocation (Allergen) or saline control challenge (Control). Data represent the individual concentration of the cytokine. The horizontal black bar denotes the median calculated from the individual data shown. $*$ : $\mathrm{p}<0.001$ for the three comparisons. IL13: interleukin-13; BALF: bronchoalveolar lavage fluid.

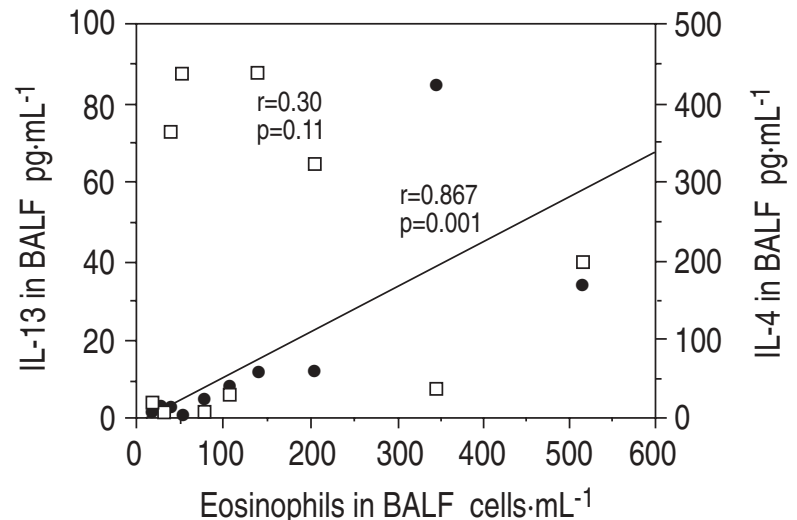

Fig. 2. - Correlation between eosinophil numbers and the concentration of IL-13 (•) as well as IL-4 (๑) measured in the BALF $18 \mathrm{~h}$ following segmental allergen challenge. Values represent the individual data obtained from the 10 subjects studied. The regression line for IL-13 is shown. IL-4: interleukin-4; IL-13: interleukin-13: BALF: bronchoalveolar lavage fluid.

$18 \mathrm{~h}$ allergen-exposed segment (fig. 1). A close correlation between the absolute number of eosinophils and the BALF, IL-13 concentration $18 \mathrm{~h}$ after allergen provocation $\left(r_{\mathrm{s}}=0.87 ; \mathrm{p}<0.002\right)$ could be calculated (fig. 2$)$, which was not observed immediately after allergen exposure or in the sham-challenged segments. There was also a weak correlation between IL-13 and lymphocyte numbers $\left(r_{\mathrm{s}}=0.66 ; \mathrm{p}<0.05\right)$, whereas no correlation existed between the cytokine level and any other cell type (neutrophils $r_{\mathrm{s}}=0.44$; macrophages $\left.r_{\mathrm{s}}=0.14 ; \mathrm{p}>0.05\right)$.

In order to validate the data obtained on IL-13, the concentration of IL-4 in BALF were assessed. As summarized in figure 3, low levels of this cytokine were measured in the $10 \mathrm{~min}$ and $18 \mathrm{~h}$ saline sham-challenged segments as well as in the $10 \mathrm{~min}$ allergen-exposed segments (10 min control: $0(0-35) \mathrm{pg} \cdot \mathrm{mL}^{-1} ; 10 \mathrm{~min}$ allergen: $0(0-52) \mathrm{pg} \cdot \mathrm{mL}^{-1} ; 18 \mathrm{~h}$ control: $0(0-45) \mathrm{pg} \cdot \mathrm{mL}^{-1}$. As with IL-13, however, significantly raised levels of IL-4 to 117.2 (median) (range 0-439) were detected in

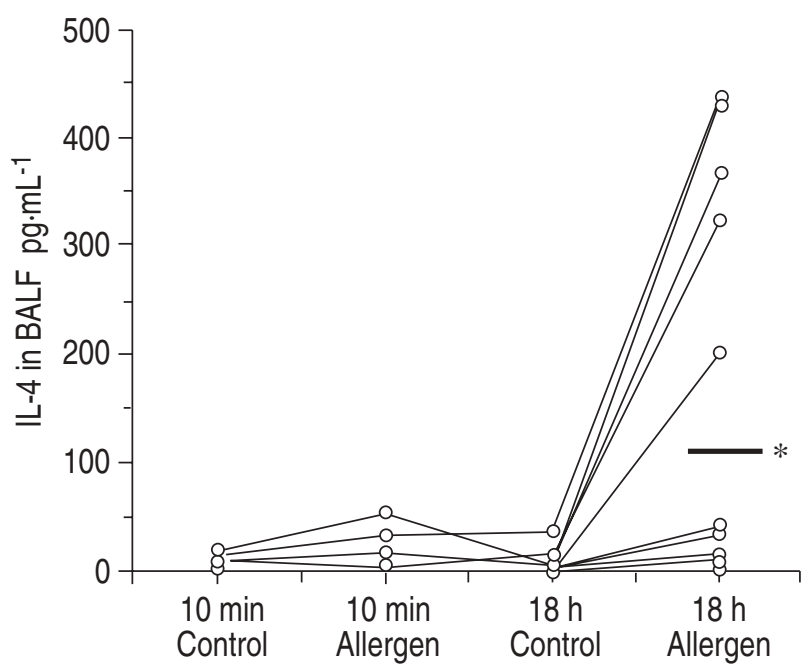

Fig. 3. - Concentrations of IL-4 in the BALF obtained $10 \mathrm{~min}$ and $18 \mathrm{~h}$ after segmental allergen provocation (Allergen) or saline control challenge (Control). Data represent the individual concentration of the cytokine. The horizontal black bar denotes the median calculated from the individual data shown. *: $\mathrm{p}<0.001$ for the three comparisons. IL-4: interleukin-4; BALF: bronchoalveolar lavage fluid. 
the $18 \mathrm{~h}$ post-allergen challenged segment in 8 out of the 10 patients studied $(\mathrm{p}<0.002)$. In contrast to IL-13, there was no correlation between IL-4 and eosinophils numbers in BALF obtained $18 \mathrm{~h}$ following segmental allergen challenge $\left(r_{s}=0.30 ; p>0.05\right)$ (fig. 2) or between IL-4 and IL-13 ( $\left.r_{s}=0.21 ; p>0.05\right)$. In addition, no significant correlation occurred between IL-4 and lymphocytes $\left(r_{s}=0.44\right)$, neutrophils $\left(r_{s}=0.49\right)$ and macrophages $\left(\mathrm{r}_{\mathrm{s}}=0.27\right)$.

\section{Discussion}

The technique of segmental allergen challenge has been demonstrated as representing a useful model to investigate inflammatory processes underlying bronchial asthma. Employing this technique we and others have demonstrated increased levels of IL-5, IL-2, IL-1, tumour necrosis factor- $\alpha$ (TNF- $\alpha$ ), IL-6, IL-8 and granulocyte/macrophage colony-stimulating factor (GM-CSF) during the late asthmatic response [24-26]. The data presented here extend these findings in three important aspects. Firstly, in contrast to a previous study [24], a significant increase in IL-4 was observed, $18 \mathrm{~h}$ following allergen challenge. Although the reason for this discrepancy is not entirely apparent, the detection of IL-4 in the present study may relate to the use of a new, more sensitive assay which did not require any further concentration of lavage fluid, thus, excluding the loss and degradation of IL-4 during the concentration process. Secondly, and even more importantly, the results presented above demonstrate that IL-13 is secreted in the course of allergic inflammation in atopic subjects with mild-to-moderate asthma. Thirdly, IL-13, but not IL-4, strongly correlates with the eosinophil numbers detected $18 \mathrm{~h}$ following local allergen exposure. Thus, in addition to IL-4, the data presented here implicate IL-13 in the immune response underlying allergic inflammation.

IL-13 is a recently cloned [12] protein secreted by activated T-cells [13]. It shows a $60 \%$ amino acid homology with a previously cloned mouse Th2 cell product, designated P600 [12, 13]. Whilst there has been no biological activity reported so far for P600, human IL-13 selectively induces vascular cell adhesion molecule-1 (VCAM-1) expression on endothelial cells in vitro $[14$, 15], and modifies cytokine secretion as well as surface antigen expression on monocytes [17-19]. In addition, IL-13 the immediate-early response gene ( $c$-fos) and surface antigen expression in human mast cells [20], promotes both human eosinophil survival and activation [21], enhances CD23/FceRII expression on resting B-cells [27], and induces the production of $\mathrm{IgE}$ and $\mathrm{IgG}_{4}$ by B-cells [16]. Although these actions resemble those of Th2-like cytokines in humans, only limited evidence has so far been presented as to whether IL-13 is produced during allergic inflammation.

At the time of submitting this manuscript, an excellent paper by HuANG et al. [28] has reported a significant enhancement both of IL-13 transcripts and secreted protein in allergen-challenged BAL compared to shamchallenged control sites of allergic asthmatics and rhinitic patients 18-24 h following allergen provocation. In contrast, they could not find a change in the BAL IL-13 level in two nonatopic patients. Although our data on the increases of IL-13 protein within the BAL compartment are in good agreement with the findings reported by HuANG et al. [28], there are a number of differences which deserve attention. For instance, in addition to measuring the cytokine level at $18 \mathrm{~h}$ postchallenge, we also assessed the secretion of IL-13 at the time of the immediate asthmatic response. In addition, we observed a strong correlation between IL-13 and eosinophil counts, which was not mentioned in the paper by HuANG et al. [28]. Furthermore, whilst we did not investigate the cellular source of IL-13, HuANG et al. [28] have convincingly shown that IL-13 is produced exclusively by mononuclear cells within the airways.

There is another significant difference between the two studies. Employing a competitive enzyme immunoassay (EIA) kit, the IL-13 concentrations detected by HuANG et al. [28] ranged $120-2,000 \mathrm{pg} \cdot \mathrm{mL}^{-1}$, which is more than 20 times the concentrations that we measured using a novel sandwich ELISA. Since the provocation techniques employed in the two studies were identical, this discrepancy may, in part, relate to the slightly higher allergen concentration employed in the present investigation. However, we also found high IL-13 levels in our samples with an EIA kit (Cytokit Red ${ }^{\mathbb{M}}$ 13; Genzyme, Boston, USA) comparable to that used by HuANG et al. [28] (data not shown), suggesting that the different cytokine concentrations most likely relate to the two detection systems used. Despite this apparent discrepancy, however, both the current study and the data reported by HuANG et al. [28] complement one another and provide strong evidence for IL-13 as a major cytokine produced during the course of asthmatic inflammation.

Local airway production of IL-13 may have several important pathophysiological consequences, which may contribute to eosinophil tissue infiltration during the inflammatory response in asthma. Firstly, as has been shown for IL-4, IL-13 may promote the VCAM-1/very late activation antigen-4 (VLA-4)-dependent accumulation of eosinophils during allergic and other inflammatory reactions due to its selective induction of VCAM-1 expression on human endothelial cells $[14,15]$. Secondly, the capacity of IL-13 to downregulate production of IL12 and IFN- $\gamma[17,29]$ by monocytes may favour the development of Th2 responses, thus, enhancing eosinophil infiltration and activation via the secretion of Th2 cell-associated cytokines, such as IL-5. Thirdly, its eosinophil survival enhancing activity [21] may represent yet another mechanism through which IL-13 may maintain the presence of eosinophils once they have arrived in the bronchial tissue. Our observation that, in contrast to IL-4, BAL IL-13 levels closely correlate with the numbers of eosinophils but not with other cell types, provides additional evidence for a possible relationship between this cytokine and eosinophil infiltration in asthmatic bronchial inflammation. Although IL-13 shows partial structural homology to and shares several biological activities as well as a common receptor component with IL-4, this latter observation, together with the finding that IL-4 does not prolong eosinophil survival, indicates that IL13 may also have some unique properties.

From data obtained in mice, it has been suggested that human IL-13, like IL-4, may represent a Th2-associated cytokine [2-4]. However, in contrast to IL-4, IL-13 is released by human Th cells expressing not only the Th2 
but also the uncommitted T-helper (Th0) or type $1 \mathrm{~T}$ helper (Th1) phenotype [30]. In addition to Th cells, IL-13 is also released by $\mathrm{CD}^{+}$cells as well as Epstein-Barr virus (EBV)-transformed B-cells [30]. In agreement with these findings, HuANG et al. [28] convincingly demonstrated that IL-13 is produced by the mononuclear cell fraction. Furthermore, in T-cell clones derived from either nonatopic subjects $[13,31]$ or from BAL of atopic asthmatics, following allergen challenge [31], IL-13 messenger ribonucleic acid (mRNA) expression was found exclusively in T-cell clones. Although we did not investigate the potential sources of IL-13, these data taken together suggest that the local production of IL-13 observed in the asthmatic subjects studied has most likely derived from various lymphocyte subsets located within the airways and activated during the course of the allergen-induced airway inflammation.

In summary, the results presented here demonstrate that exposure of asthmatic airways of atopic individuals to relevant allergen induces local interleukin-13 secretion, which parallels but does not correlate with the release of interleukin-4. Since T-cells appear to represent the major origin of interleukin-13 in humans [13, 28, 31], the study further supports the role of T-cells in orchestrating the allergic inflammation in asthma. Interleukin13 may play a critical role in this process, since it integrates several biological actions of type 2 T-helper cell cytokines implicated in the pathogenesis of asthma. Firstly, together with interleukin-4, it is involved in regulating eosinophil migration, mast cell activation, and immunoglobulin E production. Secondly, similar to interleukin-5, interleukin-13 activates eosinophils and regulates eosinophil survival. The understanding of these overlapping functions of different cytokines is of significance as regards future approaches in the treatment of asthma involving anticytokine antibodies.

Acknowledgements: The authors wish to thank S. Bock for her expert technical assistance.

\section{References}

1. Spry CFJ. In: Eosinophils: a comprehensive review and guide to the scientific and medical literature. Oxford, New York, Tokyo, Oxford University Press, 1988.

2. Kroegel C, Warner JA, Matthys H, Virchow JC Jr. Pulmonary immune cells in health and disease: the eosinophil leukocyte. Part II. Eur Respir J 1994; 7: 743-760.

3. Horn BR, Robin ED, Theodore J, von Kessel A. Total eosinophil counts in the management of bronchial asthma. N Engl J Med 1975; 292: 1152-1155.

4. Burrows B, Hasan FM, Barbee RM, Halonen M, Levowitz MD. Epidemiological observations on eosinophilia and its relation to respiratory disease. Am Rev Respir Dis 1980; 122: 709-715.

5. Durham SR, Kay AB. Eosinophils, bronchial hyperreactivity and late-phase asthmatic reactions. Clin Allergy 1985; 15: 411-418.

6. Bousquet J, Chanez P, Lacoste JY, et al. Eosinophilic inflammation in asthma. N Engl J Med 1990; 323: 10331039.

7. Corrigan CJ, Kay AB. CD4 T-lymphocyte activation in acute severe asthma: relationship to disease severity and atopic status. Am Rev Respir Dis 1990; 141: 970-977.

8. Walker C, Virchow JC Jr, Bruijnzeel PLB, Blaser K. Tcell subsets and their soluble products regulate eosinophilia in allergic and nonallergic asthma. J Immunol 1991; 146: 1829-1835.

9. Bradley BL, Azzawi M, Jacobson M, et al. Eosinophils, T-lymphocytes, mast cells, neutrophils, and macrophages in bronchial biopsy specimens from atopic subjects with asthma: comparison with biopsy specimens from atopic subjects without asthma and normal control subjects and relationship to bronchial hyperresponsiveness. J Allergy Clin Immunol 1991; 88: 661-674.

10. Walker C, Bode E, Boer L, Hansel TT, Blaser K, Virchow $\mathrm{J}-\mathrm{C}$ Jr. Allergic and nonallergic asthmatics have distinct patterns of T-cell activation and cytokine production in peripheral blood and bronchoalveolar lavage. Am Rev Respir Dis 1992; 146: 109-115.

11. Bochner B, Friedman B, Krishnaswami G, Schleimer RP, Lichtenstein LM, Kroegel C. Episodic eosinophiliamyalgia-like syndrome in a patient without L-tryptophan use: association with eosinophil activation and increased serum levels of granulocyte/macrophage colony-stimulating factor. J Allergy Clin Immunol 1991; 88: 629639.

12. McKenzie ANJ, Li X, Largaespada DA, et al. Structural comparison and chromosomal localization of the human and mouse IL-13 genes. J Immunol 1993; 150: 5436-5444.

13. Minty A, Chalon P, Derocq JM, et al. Interleukin-13 is a new human lymphokine regulating inflammatory and immune responses. Nature 1993; 362: 248-250.

14. Bochner BS, Klunk DA, Sterbinsky SA, Coffman RL, Schleimer RP. IL-13 selectively induces vascular cell adhesion molecule-1 expression in human endothelial cells. J Immunol 1995; 154: 799-803.

15. Nakajima H, Sano H, Nishimura S, Yoshida S, Iwamoto I. Role of vascular adhesion molecule-1/very late activation antigen- 4 and intercellular adhesion molecule/ lymphocyte function-associated antigen-1 interaction in antigen-induced eosinophil and T-cell recruitment into tissue. J Exp Med 1994; 179: 1145-1154.

16. Punnonen J, Aversa G, Cocks BG, et al. Interleukin-13 induces interleukin-4-independent $\mathrm{IgG}_{4}$ and $\mathrm{IgE}$ synthesis and CD23 expression by human B-cells. Proc Natl Acad Sci USA 1993; 90: 3730-3734.

17. de Waal Malefyt R, Figdor CG, Huijbens R, et al. Effects of IL-13 on phenotype, cytokine production, and cytotoxic function of human monocytes: comparison with IL-4 and modulation by IFN-gamma or IL-10. J Immunol 1993; 151: 6370-6381.

18. Herbert JM, Savi P, Laplace MC, et al. IL-4 and IL-13 exhibit comparable abilities to reduce pyrogen-induced expression of procoagulant activity in endothelial cells and monocytes. FEBS Lett 1993; 328: 268-270.

19. Muzio M, Re F, Sironi M, et al. Interleukin-13 induces the production of interleukin-1 receptor antagonists (IL$1 \mathrm{Ra}$ ) and the expression of the mRNA for the intracellular (keratinocyte) form of IL-1Ra in human monocytic cells. Blood 1994; 83: 1738-1743.

20. Nilsson G, Nilsson K. Effects of interleukin (IL)-13 on immediate-early gene expression, phenotype and differentiation of human mast cells: comparison with IL-4. Eur J Immunol 1995; 25: 870-873.

21. Luttmann W, Knöchel B, Förster M, Matthys H, Virchow JC Jr, Kroegel C. Activation of human blood eosinophils by interleukin-13. J Immunol 1996; submitted.

22. National Heart, Lung and Blood Institute. International 
consensus report on diagnosis and treatment of asthma. NHLBI publication No. 92-3091. Eur Respir J 1992; 5: 601-641.

23. Kroegel C, Liu MC, Hubbard WC, Lichtenstein LM, Bochner BS. Blood and bronchoalveolar eosinophils in allergic subjects after segmental antigen challenge: surface phenotype, density heterogeniety and prostanoid production. J Allergy Clin Immunol 1994; 93: 725-734.

24. Virchow JC Jr, Walker C, Häfner D, et al. T-cells and cytokines in bronchoalveolar lavage fluid after segmental allergen challenge in atopic asthma. Am J Respir Crit Care Med 1995; 151: 960-968.

25. Sedgwick JB, Calhoun WJ, Gleich GJ, et al. Immediate and later airway response of allergy rhinitis patients to segmental allergy challenge. Am Rev Respir Dis 1991; 144: 1274-1281.

26. Kato M, Liu MC, Stealey BA, et al. Production of granulocyte/macrophage colon-stimulating factor in human airways during allergen-induced late-phase reaction in atopic subjects. Lymphokine Cytokine Res 1992; 11: 287-292.

27. Defrance T, Carayon P, Billian G, et al. Interleukin-13 is a B-cell stimulating factor. J Exp Med 1994; 179: 135-143.

28. Huang SK, Xiao HQ, Kleine-Tebbe J, et al. IL-13 expression at the sites of allergen challenge in patients with asthma. J Immunol 1995; 155: 2688-2694.

29. Zuwarski G, de Vries JE. IL-13 and IL-4 like cytokine that acts on monocytes and B-cells, but not on T-cells. Immunol Today 1994; 15: 19-26.

30. Malefyt RD, Abrams HS, Zurawski SM, et al. Differential regulation of IL-13 and IL-4 production by human CD8+ and CD4+ Th0, Th1 and Th2 T-cells clones and EBV transformed B-cells. Int Immunol 1995; 7: 14051416.

31. Brodey K, Semper AE, Madden J, et al. Cytokine mRNA pattern in BAL T-cell clones from asthmatic airways (Abstract). J Allergy Clin Immunol 1995; 95: 279. 